\title{
Prevalence and genetic characteristics of Shigatoxigenic Escherichia coli from patients with diarrhoea in Maasailand, Kenya
}

\author{
Willie K. Sang ${ }^{1}$, Hamadi I. Boga ${ }^{2}$, Peter G. Waiyaki ${ }^{1}$, David Schnabel ${ }^{3}$, Njeri C. Wamae ${ }^{1}$, Sam \\ M. Kariuki ${ }^{1}$ \\ ${ }^{1}$ Center for Microbiology Research Laboratory, Kenya Medical Research Institute, 54840-00200, Nairobi, Kenya \\ 2 Jomo Kenyatta University of Agriculture and Technology, 62000-00200, Nairobi, Kenya \\ ${ }^{3}$ Enterics laboratory, US Army Research Unit Kenya, 606-0621, Nairobi, Kenya
}

\begin{abstract}
Introduction: Shigatoxigenic Escherichia coli strains are food-borne bacterial pathogens that may cause haemorrhagic colitis (HC) in humans which can lead to life-threatening systemic complication, including haemolytic uremic syndrome (HUS).

This study aimed to characterize and analyze virulence properties of pathogenic E. coli isolates among patients with diarrhoea from a Maasai community in Kenya.

Methodology: Stool samples from 380 patients of all ages from the Kajiado and Narok districts of Kenya were investigated for the presence of enteric bacterial pathogens by conventional and molecular methods.

Results: Bacterial diarrhoea was diagnosed in 141/380 (37.1\%) cases, of which enterotoxigenic E. coli (ETEC) compromised 29.8\%, shigatoxigenic E. coli (STEC) $24.1 \%$, enteroaggregative E. coli (EAEC) 14.2\%, enteroinvasive E. coli (EIEC) $12.8 \%$ and enteropathogenic E. coli (EPEC) $3.5 \%$. Gene analysis for STEC virulence factors showed that $52.9 \%$ isolates carried stx $1,29.4 \%$ possessed $s t x 2,14.7 \%$ carried both $s t x 1$ and $s t x 2$, and $2.9 \%$ had stx2e. $23.5 \%$ isolates carried enterohaemolysin and $20.5 \%$ isolates possessed the Intimin gene. From 9 strains that exhibited adherence, 7 contained both Intimin and Haemolysin genes. Infections with Intimin-positive STEC strains (46\%) were more frequent in patients with bloody diarrhoea, especially in children under 5 years of age, whereas Intimin-negative STEC infections dominated in adults.

Conclusion: Although STEC infection as a cause of bloody diarrhoea has not attracted much attention as a medical problem in Kenya, our findings indicate that this is a problem that must be investigated. The $24.1 \%$ isolation rate of STEC among the Maasai is one of the highest reported rates worldwide.
\end{abstract}

Key words: STEC; ETEC; EAEC; EIEC; EPEC; Intimin; Haemolysin; stx1; stx2; stx2e

J Infect Dev Ctries 2012; 6(2):102-108.

(Received 24 November 2010 - Accepted 30 May 2011)

Copyright (C) 2012 Sang et al. This is an open-access article distributed under the Creative Commons Attribution License, which permits unrestricted use, distribution, and reproduction in any medium, provided the original work is properly cited.

\section{Introduction}

Diarrhoea is a significant health problem worldwide, especially in the developing world where adequate sanitation facilities are lacking [1]. Globally diarrhoeal diseases account for almost a fifth of all deaths of children below five years of age, with an estimated 2.2 million deaths annually [2]. Epidemiological studies of diarrhoea have been reported from several African countries including South Africa [3], Gabon [4], Egypt [5] and Kenya [6]. A study conducted on travellers' diarrhoea that occurred in Europeans touring Mombasa, Kenya, reported an ETEC attack rate of 35\% [7].

In developed countries, STEC strains are the major food-borne bacterial pathogens that have been implicated in diarrhoea, HUS and HC [8-10]. One serotype, O157:H7, is the dominant serotype associated with disease in many parts of the world, but other serotypes, notably O26, O103, O111, O121, $\mathrm{O} 145$, and $\mathrm{O} 113$ are also frequently implicated in disease [11]. Cattle have long been regarded as the principal reservoir of STEC strains, including those belonging to serotype O157:H7. Several outbreaks and sporadic cases of human illness caused by infection with E. coli O157:H7, O157: H- or the other STEC isolates from dairy cattle emphasize the role of raw milk as an important vehicle of transmission [12].

The first reported cases of E. coli O157:H7 hemorrhagic colitis in Africa were made in South Africa [13] and in Kenya [14].The aim of the present study was to characterize and analyze virulence properties of pathogenic E. coli isolates among 
Table 1. Sequences of multiplex (m) PCR primers; forward (fp) and reverse (bp), (R = A and G) product and sizes

\begin{tabular}{|l|l|l|l|}
\hline Gene & Ampli & Primers & Sequence (5'-3') \\
\hline $\begin{array}{l}\text { MEinv a } \\
\text { MEinv b }\end{array}$ & 140 & invasive & $\begin{array}{l}\text { fp: TGG AAA AAC TCA GTG CCT CTG CGG } \\
\text { bp: TTC TGA TGC CTG ATG GAC CAG GAG }\end{array}$ \\
\hline $\begin{array}{l}\text { mVT1 a } \\
\text { mVT1 b }\end{array}$ & 121 & Verotoxin-1 & $\begin{array}{l}\text { fp: ACG TTA CAG CGT GTT GCA GGG ATC } \\
\text { bp: TTG CCA CAG ACT GCG TCA GTG AGG }\end{array}$ \\
\hline $\begin{array}{l}\text { mVT2a } \\
\text { mVT2b }\end{array}$ & 102 & Verotoxin-2 & $\begin{array}{l}\text { fp: TGT GGC TGG GTT CGT TAA TAC GGC } \\
\text { bp: TCC GTT GTC ATG GAA ACC GTT GTC }\end{array}$ \\
\hline $\begin{array}{l}\text { mVT2ea } \\
\text { mVT2eb }\end{array}$ & 322 & Verotoxin-animal & $\begin{array}{l}\text { fp: CCA GAA TGT CAG TAT ACT GGC GAC } \\
\text { bp: GCT GAG GAC TTT GTA ACA ATG GCT G }\end{array}$ \\
\hline $\begin{array}{l}\text { mEagga } \\
\text { mEaggb }\end{array}$ & 194 & aggregative & $\begin{array}{l}\text { fp: AGA CTC TGG CGA AAG ACT GTA TC } \\
\text { bp: ATG GCT GTC TGT AAT AGA TGA GAA C }\end{array}$ \\
\hline $\begin{array}{l}\text { mST1a } \\
\text { mST1b }\end{array}$ & 160 & Heat-stable toxin 1 & $\begin{array}{l}\text { fp: TTT CCC CTC TTT TAG TCA GTC AAC TG } \\
\text { bp: GGC AGG ATT ACA ACA AAG TTC ACA G }\end{array}$ \\
\hline $\begin{array}{l}\text { mST2a } \\
\text { mST2b }\end{array}$ & 423 & Heat-stable toxin 2 & $\begin{array}{l}\text { fp: CCC CCT CTC TTT TGC ACT TCT TTC C } \\
\text { bp: TGC TCC AGC AGT ACC ATC TCT AAC CC }\end{array}$ \\
\hline $\begin{array}{l}\text { mEaeA } \\
\text { mEAEAb }\end{array}$ & 241 & Attaching and effacing & $\begin{array}{l}\text { fp: TGA GCG GCT GGC ATG AGT CAT AC } \\
\text { bp: TCG ATC CCC ATC GTC ACC AGA GG }\end{array}$ \\
\hline $\begin{array}{l}\text { mLT1a } \\
\text { mLT1b }\end{array}$ & 360 & Heat-labile toxin 1 & $\begin{array}{l}\text { fp: TGG ATT CAT CAT GCA CCA CAA GG } \\
\text { bp: CCA TTT CTC TTT TGC CTG CCA TC }\end{array}$ \\
\hline $\begin{array}{l}\text { mCNF1a } \\
\text { mCNF1b }\end{array}$ & 552 & Cytotoxic necrotizing-1 & $\begin{array}{l}\text { fp: GGC GAC AAA TGC AGT ATT GCT TGG } \\
\text { bp: GAC GTT GGT TGC GGT AAT TTT GGG }\end{array}$ \\
\hline $\begin{array}{l}\text { mCNF2a } \\
\text { mCNF2b }\end{array}$ & 839 & Cytotoxic necrotizing-2 & $\begin{array}{l}\text { fp: GTG AGG CTC AAC GAG ATT ATG CAC TG } \\
\text { bp: CCA CGC TTC TTC TTC AGT TGT TCC TC }\end{array}$ \\
\hline
\end{tabular}

*Ampli- Amplicon Source: [Ref 17]

patients with diarrhoea from the Maasai community who sought treatment in the Entosopia clinic, Kajiado district, and in the Narok District Hospital. These two districts are dominated by the pastoralist Maasai community and have previously reported high incidents of bloody diarrhoea. We hypothesized that STEC plays a significant role as a pathogen of bloody diarrhoea within the Maasai community.

\section{Methodology}

\section{Specimen collection}

The protocol for this study was granted approval by both the KEMRI Scientific Steering Committee as well as the National Ethical Review Committee.

After obtaining informed consent, stool samples were collected between August 2004 and July 2005 from 380 outpatients of all ages presenting with diarrhoea who were not on antibiotics in the last 72 hours. In total, 318 samples were obtained from the Narok District Hospital and 62 from the Entosopia clinic. Diarrhoea was defined as at least 3 loose stools in 24 hours, or any number of watery stools.

Collection was done in sterile plastic containers. The specimens were transferred into Cary-Blair transport media (MML Diagnostics Inc, Troutdale, Oregon, USA), labeled only with a unique study number, and then placed in an insulated box with ice packs and transported to the Kenya Medical Research Institute laboratory where they were processed within six hours of collection.

All stool samples were plated onto MacConkey agar, Xylose-Lysine-Deoxycholate agar (XLD), Sorbitol-MacConkey agar and Campylobacter bloodfree agar. Initially selenite broth was used for enrichment purposes. The plates were incubated aerobically at $37^{\circ} \mathrm{C}$ for 18 to 24 hours, with the exception of Campylobacter plates, which were incubated at $42^{\circ} \mathrm{C}$ in microaerophilic conditions for 48 hours [15].

After overnight growth at $37^{\circ} \mathrm{C}$, one to two suspect colonies each of Shigella and Salmonella and five to ten single colonies with typical E. coli morphology were selected and characterized on the basis of their biochemical reactions using BBL Enterotubes II (Becton Dickson Microbiology Systems, Sparks, Maryland USA).

The strains identified as Salmonella, Shigella, or E. coli by their colonial morphology and biochemical properties were further serotyped using $\mathrm{O}$-antigen and H-antigen antisera (Denka Seiken Co LTD, Tokyo, Japan) by slide agglutination assays as previously described [16]. 
Figure 1. Multiplex PCR for detection of E. coli virulence factors. Agarose gel electrophoresis of the PCR representative DNA fragments amplified by 11 multiplex PCR products of E. coli pathotypes

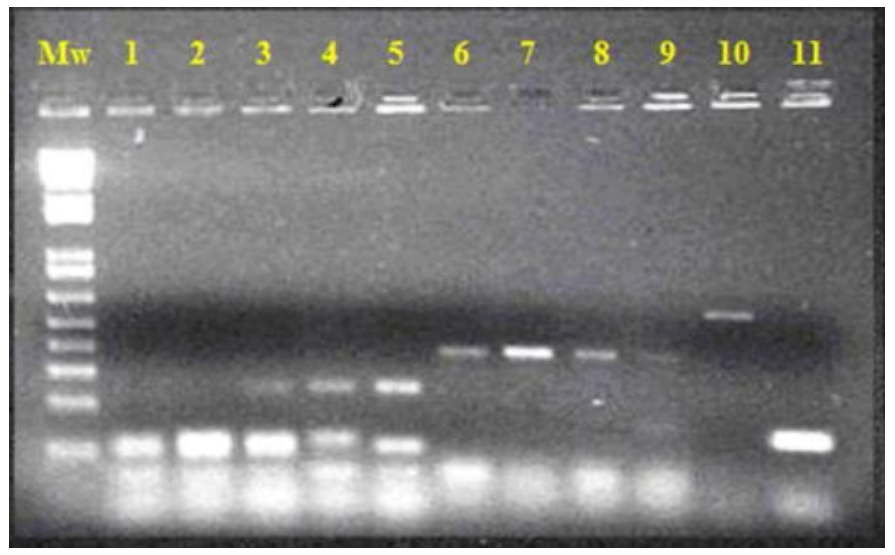

Identification of virulence markers by multiplex PCR

A multiplex PCR assay allowed the detection of eleven trait genes or virulence markers in enteropathogenic E. coli serotypes. Primers for amplifying segments of genes of the Shiga toxins (stx1, stx2, and stx2e), Cytotoxin necrotising factors (CNFI and CNF2), attaching and effacing mechanisms (eaeA), enteroaggregative (EAEC), enteroinvasive mechanism (EIEC), and heat-labile (LT) and heatstable (ST1 and ST2) toxins were used as described previously [17].

Details of the nucleotide sequence, the specific gene region amplified, and the size of the PCR product for each primer pair are given in Table 1. PCR was performed in $0.2 \mathrm{ml}$ Eppendorf tubes in a PTC-200 thermal cycler (MJ Research Inc, Watertown, Massachusetts, USA) in a reaction volume of $25 \mu \mathrm{l}$. The DNA template, $(2 \mu 1$ of bacterial suspension) was added to a $25 \mu 1$ reaction mixture containing $2.0 \mu \mathrm{l}$ of $10 \mathrm{mM}$ mix deoxynucleotide triphosphate (dNTPs), $2.5 \mu \mathrm{l}$ of $\mathrm{MgCl}_{2}(25 \mathrm{mM}), 2.5 \mu \mathrm{l} 10 \mathrm{X}$ buffer solution, and $1.25 \mu \mathrm{l}$ of each of the PCR primer with a concentration of $0.5 \mathrm{pmol} / \mu \mathrm{l}$ (Bioserve Biotechnologies, Laurel, MD.USA). Finally, $0.3 \mu \mathrm{l}$ of Taq Polymerase (5U/ $\mu$ l), (Applied Biosystems, Roche Molecular, Inc, and Branchbury, New Jersey, USA) was added to this reaction mix. Base sequences and predicted sizes of amplified products for the specific oligonucleotide primers were used as controls in the study.

\section{Detection of Vero cytotoxin (VT or Stx)}

The production of Shiga toxin by stx PCR-positive strains was checked by using the Vero cell cytotoxicity assay with slight modifications [18]. Vero cells
(African green monkey kidney cells; ATCC CRL 1587) were grown at $37^{\circ} \mathrm{C}$ in EMEM (Seromed, Berlin, Germany) supplemented with $10 \%$ fetal calf serum (Seromed), 1\% L-glutamine (Life Technologies, Paisley, Scotland), 100,000 U of penicillin per liter, $100 \mathrm{mg}$ of streptomycin per liter, $25 \mu \mathrm{g}$ of amphotericin B per liter, and 1\% minimal essential medium vitamin solution (Life Technologies) in an atmosphere of $5 \% \mathrm{CO}_{2}$. Briefly, the bacterial strains were inoculated into $10 \mathrm{ml}$ of trypticase soy broth (Difco laboratories, Detroit, Michigan, USA) and incubated at $37^{\circ} \mathrm{C}$ overnight. After centrifugation at $12,000 \times \mathrm{g}$ for five minutes, supernatants were filtered through a Millipore filter (pore size $0.45 \mu \mathrm{m}$ ) (PolyLabo, Molsheim, France) and screened for Verocytotoxicity. Twofold serial dilutions of the culture filtrates were done in 96-well flat-bottom microtiter plates (Nunc, Roskilde, Denmark) (100 $\mu \mathrm{l}$ per well; 12 wells per strain; dilutions from $1 / 2$ to $1 / 2,048)$. A total of $20 \mu \mathrm{l}$ of the test filtrate containing $10^{5}$ Vero cells in suspension were added to each well. The culture plates were incubated for 24 hours at $37^{\circ} \mathrm{C}$ in a $5 \% \mathrm{CO}_{2}$. After 24 hours, cell monolayers were washed with phosphate-buffered saline $(\mathrm{pH}$ 7.2) and the cells fixed with methanol for five minutes and thereafter stained with Giemsa $(5 \%$ w/v in phosphate buffer). After 45 minutes the monolayer was washed three times with distilled water and dried. The cells were examined microscopically. E. coli K-12 C600 was used as a negative control.

The toxin titers were expressed as the reciprocals of the highest dilution that caused cytotoxicity in 50\% of Vero cells after 4 days of incubation, as judged by the dye intensity and microscopic observation.

\section{Results}

\section{Isolation of bacteria}

Stool samples from a total of 380 patients were tested by culture for the presence of enteric bacterial pathogens. These patients came from two districts, Narok and Kajiado, which are occupied mainly by the Maasai community. The study was conducted at the Narok District Hospital where 318 patients were examined and at the Entosopia clinic in Kajiado where 62 patients were recruited.

Bacterial diarrhoea was observed in 141 of 380 patients (37.1\%). Diarrhoeagenic E. coli including ETEC, STEC, EAEC, EIEC, and EPEC were detected. The distribution of these 141 cases among the different E. coli pathotypes and other bacterial pathogens is shown in Table 1. ETEC comprised 42/141 (29.8\%), 
Table 2. Prevalence of enteric bacterial pathogens from 380 patients

\begin{tabular}{|c|c|c|}
\hline Enteric pathogen & $\begin{array}{c}\text { Number of } \\
\text { patients }\end{array}$ & $\begin{array}{c}\text { \% of infected } \\
\text { patients }\end{array}$ \\
\hline ETEC & 42 & $11.1 \%$ \\
\hline STEC & 34 & $8.9 \%$ \\
\hline EAEC & 20 & $5.3 \%$ \\
\hline Shigella & 19 & $5.0 \%$ \\
\hline EIEC & 18 & $4.7 \%$ \\
\hline EPEC & 5 & $1.3 \%$ \\
\hline Salmonella & 3 & $0.78 \%$ \\
\hline
\end{tabular}

STEC 34/141 (24.1\%), EAEC 20/141 (14.2\%), EIEC 18/141 (12.8\%), and EPEC 5/141 (3.5\%). Other enteric pathogens such as Shigella and Salmonella comprised 19/141 (13.5\%) and 3/141 (2.1\%), respectively.

Age distribution of diarrhoeal patients from whom STEC was isolated

The age distribution of patients with diarrhoea ranged between 2.4 months and 54 years. The median age was eight years while the mode was 45 years. The samples were divided into three distinctive groups based on the ages of the participants as follows: under five years; between five and 18 years; and above 18 years. STEC was isolated from $56 \%$ of females and $44 \%$ of males in all groups. The distribution of STEC infected patients per age groups were as follows: $50 \%$ were under five years of age, $18 \%$ were between 5 and 18 years and $32 \%$ were over 18 years (Table 2 ).

\section{Multiplex PCR}

Multiplex PCR analysis of 380 stool samples from diarrhoeal patients detected 11 of the major virulence genes of E. coli with four multiplex PCRs. The following four combinations of primers gave distinct and adequate amplification of their respective targets: VT1, VT2, VT2e and eaeA; CNF1 and EAEC; CNF2 and EIEC; and LTI, ST1 and ST2. The O157:H7 positive control strain yielded all three specific gene products in question or expected (Stx1, Stx2 and eaeA), while no products were obtained from the $E$. coli negative control.

The combination of the different primers used in the multiplex reaction to amplify more genes in a single reaction is represented in Figure 1. With respect to the stx genes, analysis showed that all STEC (EHEC) strains examined had PCR products for VT1, VT2 or both; and seven among them harbored the eaeA gene that codes for Intimin (Table 3 ).

The prevalence of STEC virulence factors within diarrhoeal cases

A total of 34 patients were infected with STEC bacteria serogroups: O86, O6, O55, O28, O27, O25, O164, O151, O111, O148, O128, O126 and O78. The distributions of STEC infection with various virulence traits were as follows: 18 (52.9\%) of 34 patients harbored E. coli containing stxl toxin genes, and all of them were $100 \%$ positive for Vero cell cytotoxic effect but had no other virulence factors tested (Table 3). The 10 isolates $(29.4 \%)$ that harbored the $s t x 2$ toxin gene only were $100 \%$ positive for Vero cell cytotoxicity assay and $40 \%$ positive for Haemolysin gene. They were also $30 \%$ positive for Intimin gene. The other five $(14.7 \%)$ carried both stx 1 and stx 2 toxin genes and were also $100 \%$ positive for cytotoxicity and $80 \%$ positive for both Haemolysin and Intimin genes, while one $(2.9 \%)$ which had stx2e toxin gene had no virulence factors detected (Figure 2).

\section{Discussion}

Previous studies in Kenya have documented the prevalence of some traditionally recognized agents of

Table 3. Prevalence of virulence factors in STEC bacteria

\begin{tabular}{|l|c|r|r|r|r|r|}
\hline Virulence factors & \multicolumn{2}{|c|}{ Cytotoxic } & $\%$ & $\mathrm{~N}$ & \multicolumn{2}{l|}{ eaeA } \\
\hline STEC type & $\mathrm{N}$ & 18 & $100.00 \%$ & 0 & $\mathrm{~N}$ & 0 \\
\hline VT1 alone & 10 & $100.00 \%$ & 4 & $0.00 \%$ & 0 & $0.00 \%$ \\
\hline VT2 alone & 5 & $100.00 \%$ & 4 & $40.00 \%$ & 3 & $30.00 \%$ \\
\hline VT1+VT2 & 1 & $100.00 \%$ & 0 & $0.00 \%$ & 4 & 0 \\
\hline VT2e & & & $0.00 \%$ & $0.00 \%$ \\
\hline
\end{tabular}

$\mathrm{N}=$ number 
Figure 2. Test for Vero cytotoxic effect using different titers

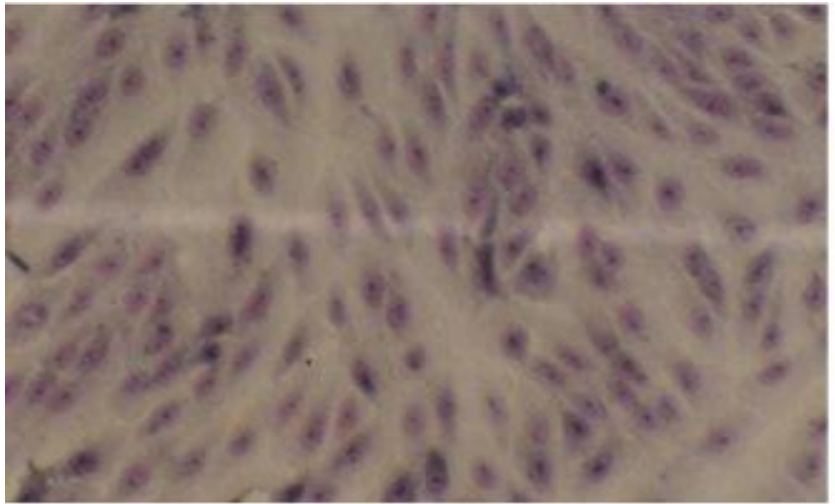

A

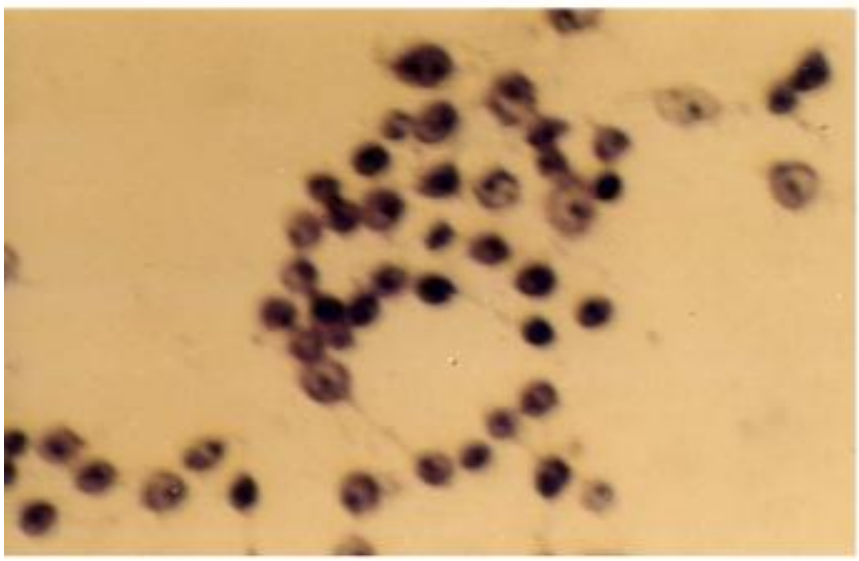

C

A - The Vero cell line monolayer used as control 20x

B - Cytotoxic effect of Vero cell line at dilutions 1:64, 20x

C - Cytotoxic effect of Vero cell line at dilutions 1:32, 40x

D - Cytotoxic effect of Vero cell line at dilutions 1:4, 40x

diarrhoea such as Shigella, Salmonella and ETEC $[6,14,19]$. This study is the first to address the prevalence of STEC in stool samples from the Maasai community where poor hygiene conditions in the homesteads are common. Furthermore, this study correlated the presence of specific recognized or putative virulence factors with disease or severity of disease.

In the present study serotype O157:H7 or its nonmotile variant O157:H- was not isolated. The STEC strains that were isolated comprised the following serogroups: O86, O6, O55, O28, O27, O25, O164, O151, O111, O148, O128, O126 and O78. Several of these isolates, $8 / 34(23.5 \%)$, possessed some of the characteristics of virulence factors similar to those of the $\mathrm{O} 157: \mathrm{H} 7$ which cause serious diseases in humans. It is noteworthy that such a wide spectrum of different STEC serotypes can exist within a particular region.

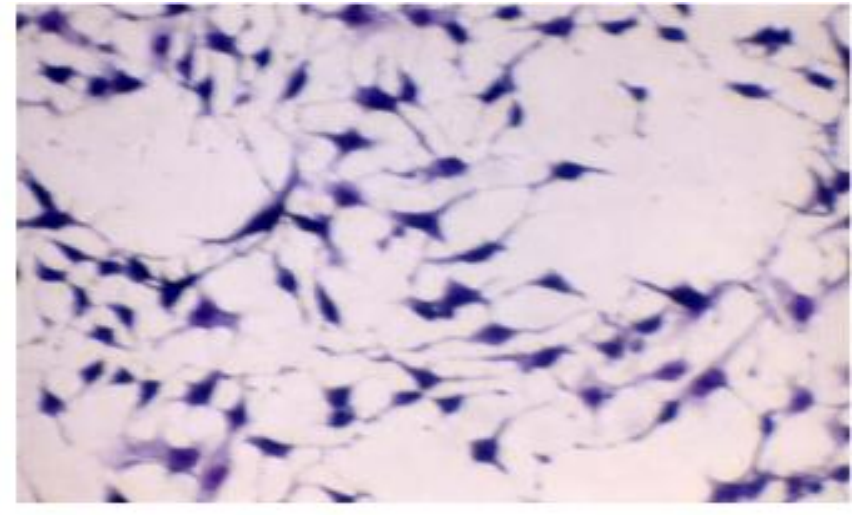

B

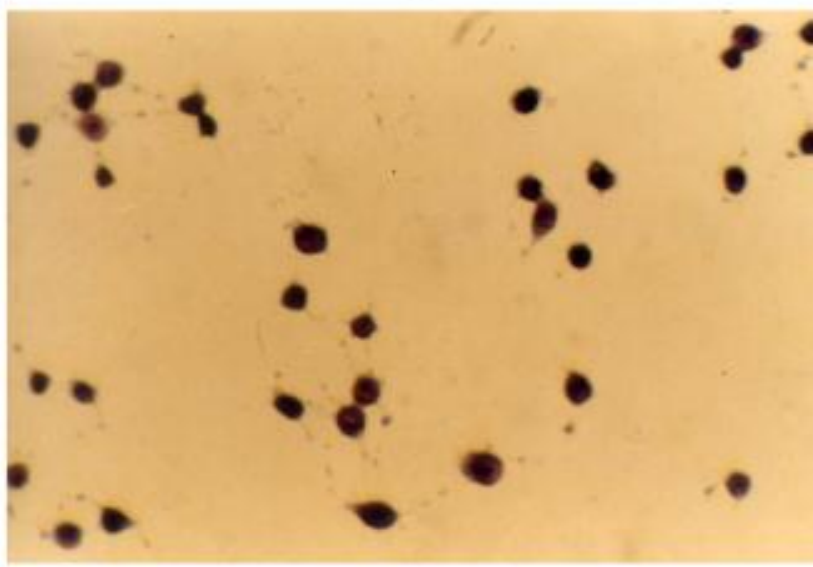

D
The overall results show that ETEC and STEC are major bacterial pathogens in the community studied with a prevalence of $29.8 \%$ and $24.1 \%$ respectively. The large proportion of diarrhoeal cases in our study $(62.9 \%)$ from whom no recognized pathogen was identified raises a number of issues. First, many different organisms may cause diarrhoea and it is not possible in a study such as this to screen specimens for the entire range of potential enteropathogens. Second, even when specifically sought, some pathogens may not be detected by conventional microbiological methods because of excretion in insufficient numbers. A study by Joyce et al. showed a prevalence of $13 \%$ enteropathogenic E. coli among Maasai children under five years of age [22]. However, their study did not characterize $E$. coli into their pathotypes.

Studies from different countries have also shown that humans can be infected with a large spectrum of 
serologically different STEC types [20]. STEC is associated with a broad spectrum of illnesses in humans including non-bloody and bloody diarrhoea, haemorrhagic colitis (HC) and the often deadly haemorrhagic uremic syndrome (HUS) [9].

Finding the newly described diarrhoeal pathogens, especially of varying STEC serotypes, in our patients in a relatively higher proportion $(24.1 \%)$ than those which have been reported in many countries including Switzerland 1\% [21], Germany 1\% [22], Belgium $0.2 \%$ [23], and 3\% [24] France, is of great clinical importance. Notably, some of the serotypes detected $(\mathrm{O} 86, \mathrm{O} 28)$ in this study were not those typically known to be associated with STEC and nearly all the strains carry genes known as potential virulence factors associated with STEC infections. The O25 and O111 serogroups observed here have been reported at higher frequencies varying from $9 \%$ to $12 \%$ in Chile and $3 \%$ to $15 \%$ in Argentina among HUS patients $[25,26]$.

Although STEC infection has not attracted much attention as a medical problem in Kenya, the findings from this study have indicated that this is an existing problem that needs to be investigated.

\section{Acknowledgements}

We gratefully thank the Walter Reed Global Emerging Infections Surveillance (GEIS) Program through the direction of Dr. Sam Martin, Dr. Rodney Coldren and Dr. Sheryl Bedno for the $\mathrm{PhD}$ sponsorship award and for providing research materials to successfully complete this research project. We also appreciate the role played by Godwin Mollel from the start of the project to completion. We further acknowledge the Director of KEMRI for the support in allowing permission to publish this manuscript.

\section{References}

1. Okeke IN, Lamikanra A, Steinruck H, Kaper JB (2000) Characterization of Escherichia coli strains from cases of childhood diarrhea in provincial southwestern Nigeria. J Clin Microbiol 38: 7-12.

2. Black RE, Morris SS, Bryce J (2003) Where and why are 10 million children dying every year? Lancet 361: 2226-2234.

3. Househam KC, Mann MD, Bowie MD (1988) Enteropathogens associated with acute infantile diarrhea in Cape Town. S Afr Med J 73: 83-87.

4. Presterl E, Zwick RH, Reichmann S, Aichelburg A, Winkler S, Kremsner P, Granigner W (2003) Frequency and virulence properties of diarrheagenic Escherichia coli in children with diarrhea in Gabon. Am J Trop Med Hyg 69: 406-410.

5. Rao MR, Abu-Elyazeed R, Salvarino SJ, Naficy AB, Wierzba TF, Abdel-Messih I, Shaheen H, Frenck RW, Svennerholm AM, Clemens JD (2003) High disease burden of diarrhea due to Enterotoxigenic Escherichia coli among rural Egyptian infants and young children. J Clin Microbiol 41: 4862-4864.

6. Saidi SM, Iijima Y, Sang WK, Mwangudza AK, Oundo JO, Taga K, Waiyaki PG, Honda T (1997) Epidemiological study on infectious diarrhea diseases in children in a coastal rural area of Kenya. Microbiol Immunol 41: 773-778.

7. Shaheen HI, Kamal KA, Wasfy MO, El-Ghorab NM Lowe B, Steffen R, Kodkani N, Amsler L, Waiyaki P, David JC, Khalil SB, Peruski LF Jr (2003) Phenotypic diversity of Enterotoxigenic E. coli (ETEC) isolated from cases of traveler's diarrhea in Kenya. Int J Infect Dis 7: 35-38.

8. Armstrong GL, Hollingsworth J, Morris JG Jr (1996) Emerging foodborne pathogens: Escherichia coli O157:H7 as a model of entry of a new pathogen into the food supply of the developed world. Epidemiol Rev 18: 29-51.

9. Griffin PM and Tauxe RV (1991) The epidemiology of infections caused by Escherichia coli O157:H7, other enterohemorrhagic E. coli, and associated hemolytic uremic syndrome. Epidemiol Rev 13: 60-98.

10. Karmali MA (1989) Infection by Verotoxin-producing Escherichia coli. Clin Microbiol Rev 2: 15-38.

11. Tamura K, Sakazaki R, Murase M, Kosaka Y (1996) Serotyping and categorization of Escherichia coli strains isolated between 1958 and 1992 from diarrheal diseases in Asia. J Med Microbiol 45: 353-358.

12. Reitsma CJ and Henning DR (1996) Survival of enterohemorrhagic Escherichia coli O157:H7 during the manufacture of cheddar cheese. J Food Prot 59: 460-464.

13. Browning NG, Botha JR, Sacho H, Moore PJ (1990) Escherichia coli O157:H7 haemorrhagic colitis: report of the first South African case. S Afr J Surg 28: 28-29.

14. Sang WK, Saidi SM, Yamamoto H, Ezaki T, Iida T, Yoh M, Honda T (1996) Hemorrhagic colitis due to Escherichia coli O157:H7 in Kenya. J Trop Pediatr 42: 118-119.

15. Chan FT, Mackenzie AM (1984) Advantage of using enrichment culture techniques to isolate Campylobacter jejuni from stools. J Infect Dis 149: 481-482.

16. Bettelheim KA, and Thampson CJ (1987) New method of serotyping Escherichia coli; Implementation, and verification. J Clin Microbiol 25: 781-786.

17. Pass MA, Odedra R., Batt RM (2000) Multiplex PCRs for Identification of Escherichia coli virulence genes. J Clin Microbiol 38: 2001-2004.

18. Konowalchuk J, Speirs JI, Stravric S (1977) Vero response to a cytotoxin of Escherichia coli. Infect Immun 18: 775-779.

19. Joyce T, McGuigan KG, Elmore-Meegan M, Conroy RM (1996) Prevalence of enteropathogens in stools of rural Maasai children under five years of age in the Maasailand region of the Kenya Rift Valley. East Afr Med J 73: 59-62.

20. Boerlin P, McEwen SA, Boerlin-Petzold F, Wilson JB, Johnson RP, Gyles CL (1999) Associations between virulence factors of Shiga toxin-producing Escherichia coli and disease in humans. J Clin Microbiol 37: 497-503.

21. Burnens AP, Boss P, Orskov F, Schaad UB, Muller F, Heinzle R, Nicolet J (1992) Occurrence and phenotypic properties of verotoxin producing Escherichia coli in sporadic cases of gastroenteritis. Eur J Clin Microbiol Infect Dis 11: 631-634.

22. Karch H, Meyer T, Rusman H, Heesemann J (1992) Frequent loss of Shiga-like toxin genes in clinical isolates of Escherichia coli upon subcultivation. Infect Immun 60: 34643467.

23. Piérard D, Muyldermans G, Moriau L, Stevens D, Lauwers S (1998) Identification of new verocytotoxin type 2 variant Bsubunit genes in human and animal Escherichia coli isolates. $\mathrm{J}$ Clin Microbiol 36: 3317-3322.

24. Pradel N, Livrell V, de Champs C, Reynaud A, Scheutz F, Joly B, Forestier C (2000) Prevalence and characterization of 
Shiga-toxin producing Escherichia coli isolated from cattle, food and children during a one-year prospective study in France. J Clin Microbiol 38: 1023-1031.

25. Rios M, Prado V, Trucksis M, Arellano C, Borie C, Alexandre M, Fica A, Levine MM (1999) Clonal diversity of Chilean isolates of enterohemorrhagic Escherichia coli from patients with hemolytic-uremic syndrome, asymptomatic subjects, animal reservoirs, and food products. J Clin Microbiol 37: 778-781.

26. Rivas M, Sosa-Estani S, Rangel J, Caletti MG, Vallés P, Roldán CD, Balbi L, Marsano de Mollar MC, Amoedo D, Miliwebsky E, Chinen I, Hoekstra RM, Mead P, Griffin PM (2008) Risk factors for sporadic Shiga toxin-producing
Escherichia coli infections in children, Argentina. Emerg Infect Dis 14: 763-771.

\section{Corresponding author}

Willie K. Sang

Address: PO Box 54840-00200

Nairobi, Kenya

Telephone: (254) (020) 2722541

Fax: (254) (020) 2720030

Email: wsang@wrp-nbo.org

Conflict of interests: No conflict of interests is declared. 